\title{
Characterizing bi-temporal patterns of land surface temperature using landscape metrics based on sub-pixel classifications from Landsat TM/ETM+
}

Youshui Zhang $^{\mathrm{a}, *}$, Heiko Balzter ${ }^{\mathrm{b}, \mathrm{c}}$, Chuncheng Zou ${ }^{\mathrm{a}}$, Hanqiu Xu ${ }^{\mathrm{d}}$, Fei Tang ${ }^{\mathrm{d}}$

${ }^{a}$ College of Geography, Fujian Normal University, Fuzhou 350007, P.R.China

${ }^{\mathrm{b}}$ University of Leicester, Centre for Landscape and Climate Research, University Road, Leicester, LE1 7RH, UK

${ }^{\mathrm{c}}$ National Centre for Earth Observation, University of Leicester, University Road, Leicester, LE1 7RH, UK

${ }^{\mathrm{d}}$ College of Environment and Resources, Fuzhou University, Fuzhou 350108, P.R.China

* Corresponding author. Tel.: +86 5918346 5214; fax: +86 59183465397.

E-mail address: zhangyoushui@sina.com (Y. S. Zhang), hb91@le.ac.uk (H. Balzter).

\section{Abstract}

behavior of thermal environments. There is a lack of research generating landscape metrics

from discretized percent impervious surface area data (ISA), which can be used as an

21 indicator of urban spatial structure and level of development, and quantitatively characterizing 22 the spatial patterns of landscapes and land surface temperatures (LST). In this study, linear spectral mixture analysis (LSMA) is used to derive sub-pixel ISA. Continuous fractional cover thresholds are used to discretize percent ISA into different categories related to urban 25 land cover patterns. Landscape metrics are calculated based on different ISA categories and 26 used to quantify urban landscape patterns and LST configurations. The characteristics of LST 27 and percent ISA are quantified by landscape metrics such as indices of patch density, 28 aggregation, connectedness, shape and shape complexity. The urban thermal intensity is also 29 analyzed based on percent ISA. The results indicate that landscape metrics are sensitive to the 
variation of pixel values of fractional ISA, and the integration of LST, LSMA. Landscape metrics provide a quantitative method for describing the spatial distribution and seasonal variation in urban thermal patterns in response to associated urban land cover patterns.

Keywords: Urban; Linear spectral unmixing; Percent impervious surface area; Threshold continuum; Land surface temperature; Landscape metrics

\section{Introduction}

The urban heat island (UHI) effect is due primarily to the increased use of impervious surface materials, the decrease of vegetation cover and water-permeable surfaces and the emission of heat by human activities (Kato and Yamaguchi, 2005). Its magnitude is exacerbated by global climate change. Land surface temperature (LST) is impacted by surface-atmosphere interactions and energy fluxes between the land surface and the atmosphere (Wan and Dozier, 1996). Past studies measuring LST and heat fluxes have been mainly based on ground observations and digital model simulation (Voogt and Oke, 2003; Weng et al., 2004). Generally, ground observation studies describe detailed seasonal variations of thermal environments, but the number of observations is usually limited due to physical and economic constraints (Voogt and Oke, 2003). Advances in remote sensing have enabled the use of satellite data at various spatial and temporal resolutions for estimating surface temperatures over entire urban regions (Xian and Crane, 2006; Zhang et al., 2009). Thus, satellite remote sensing has been used extensively for a description of thermal patterns and simple correlation analysis of spatially heterogeneous urban land use patterns (Pu et al., 2006; Amiri et al., 2009; Imhoff et al., 2010; Deng et al., 2013).

Many previous remote sensing studies of the urban environment have used the Normalized Difference Vegetation Index (NDVI) as a descriptor for urban climate patterns (Lo et al., 1997; Gallo et al., 1999; Yuan and Bauer, 2007). However, NDVI measurements are subject to seasonal variations due to vegetation phenological cycles. Furthermore, the relationship between NDVI and LST is known to be non-linear (Price, 1990; Owen et al., 1998; Chen et al., 2006). Therefore, NDVI alone is considered insufficient for quantitatively 
studying urban environments. Impervious surfaces are defined as any impenetrable material, such as rooftops, roads, parking lots and other man-made surfaces that prevent infiltration of water into the soil (Arnold and Gibbons, 1996).

Impervious surface areas (ISA) are stable and not affected by seasonal changes, and are therefore an important parameter for the analysis of LST and urban thermal patterns (Lu and Weng, 2006; Zhou et al., 2014). At the scale of 20-50 m it is common in many cities to have mixed pixels that are only partially covered by ISA. Due to this mixed pixel problem, in many cities traditional per-pixel classifiers cannot effectively handle the complex fine-scale urban landscape patterns. A solution is to use percent ISA rather than a crisp classification to characterize urban land cover patterns (Lu and Weng, 2006; Frazier and Wang, 2011). The vegetation-impervious-soil (VIS) model assumes that the spectral signature of land cover in urban environments is a linear combination of vegetation, impervious surfaces, and soil when water surfaces can be ignored (Ridd, 1995). The VIS model is an effective way of coping with the mixed-pixel problem (Smith, 1990; Rashed, 2008; Michishita et al., 2012). Continuous percent ISA information on a scale from $0 \%$ to $100 \%$ also reveals central business districts (CBD) and urban residential areas with varying densities and patterns, rural developed centers and relatively undeveloped areas (Zhang et al., 2009). For the purpose of developing effective climate change adaptation strategies in urban environments it is important to analyze the relationship between LST and percent ISA in urban environments as an alternative approach to traditional land cover based methods.

Landscape/land use/land cover patches in a region have different sizes, shapes and spatial arrangements. These contribute to the spatial heterogeneity of the landscape, and have significant effects on urban thermal environments (Zhang et al., 2013; Liu and Weng, 2008; Maimaitiyiming et al., 2014). To understand the dynamics of patterns and processes and their interactions in the landscape, methods for accurately quantifying the spatial landscape patterns and their seasonal changes are required. A series of landscape metrics have been developed to characterize spatial landscape patterns and their impacts on the environment (Frazier and Wang, 2011; Liu and Weng, 2008; Riitters, 1995; Gustafson, 1998; Yue et al., 
2007). When applied to the study of urban LST patterns, these landscape metrics have often been calculated based on 'hard', binary classifications of ISA and other land cover categories (Liu and Weng, 2008; Li et al., 2011).

However, in the published literature such landscape metrics have not yet been calculated from percent ISA, i.e. a 'soft' classification of ISA, to our knowledge. This may be because these metrics cannot be computed directly for percent ISA. This paper has tested a new method for discretizing sub-pixel ISA data at gradually increasing thresholds using two different approaches: the range approach and the threshold continuum approach. Based on converting continuous ISA fractions to discrete ISA classes by these two methods, landscape metrics can be calculated for each discrete ISA class. This provides the advantage that sub-pixel information on percent ISA provides more realistic descriptions of urban landscape structure than 'hard' land cover classifications. In addition to the absolute fraction of ISA, the effects of different spatial patterns of percent ISA on the magnitude of urban LST is quantified here with landscape metrics including the indices of patchiness, edge length, fractal dimension and texture. Since these metrics are sensitive to the variations of the sub-pixel ISA values, we can analyze quantitatively how different spatial patterns of different percent ISA zones contribute to the overall urban thermal characteristics and patterns in a city. The results of this analysis of micrometeorological seasonal variability will provide valuable information for the validation of predicted climatic change at the local scale.

\section{Study area and data}

The study area is Fuzhou City, located on the southeast coast of China (Fig. 1). Like many other Chinese cities, the population of Fuzhou is rapidly increasing (from 5.2 million in 1989 to 6.5 million in 2001) leading to increased urban expansion. Compared with the warmer summer climate, the weather in Fuzhou in spring, autumn and winter is relatively similar. Therefore, two images were selected to quantify the effects of the two major climatic seasons: A Landsat 5 TM image (acquired on June 15, 1989) and a Landsat 7 ETM+ image (acquired on March 4, 2001). Landsat bands 1-5 and 7 images have a spatial resolution of 30 
6

$\mathrm{m}$, and the thermal infrared band (band 6) has $120 \mathrm{~m}$ spatial resolution for TM and $60 \mathrm{~m}$ for ETM+.

Fig. 1. Location of the study area showing the Landsat 7 ETM+ image $($ Red $=$ band 4, Green = band 3, Blue = band 2). This Figure is reproduced from Zhang, Y., Balzter, H., Wu, X. (2013).

An IKONOS image acquired on 29 October 2000 with 4 m spatial resolution and aerial photographs acquired on 20 May 1988 with 2 m spatial resolution were used to validate the retrievals of ISA from Landsat data. All images were reprojected to the Universal Transverse Mercator (UTM) projection, based on the geocoded high resolution IKONOS image and aerial photograph. The RMSE of the georectification was $<0.3$ pixels $(<9 \mathrm{~m})$.

We used the radiative transfer equation to retrieve LST from the Landsat data. This method has three steps (Zhang et al., 2009; Yuan and Bauer, 2007): The first step is to convert the digital numbers of the bands to top-of-atmosphere (TOA) radiance (Schroeder et al., 2006), and then to further convert TOA radiance of visible and near-infrared bands to surface reflectance by applying an atmospheric correction. Step 2 is to convert TOA radiance of the thermal band to surface-leaving radiance using the atmospheric correction tool MODTRAN 4.1 to remove the effects of the atmosphere (Berk et al., 1999). The surface-leaving radiance $\mathrm{L}_{\mathrm{T}}$ is calculated using Eq. (1) (Barsi et al., 2005):

$$
\mathrm{L}_{\mathrm{T}}=\left(\mathrm{L}_{\lambda}-\mathrm{L}_{\mu}-\tau(1-\varepsilon) \mathrm{L}_{\mathrm{d}}\right) / \tau \varepsilon
$$

where $L_{\mu}, \tau$ and $L_{d}$ are respectively the upwelling radiance, atmospheric transmission and downwelling radiance, and $\varepsilon$ is the emissivity of the surface specific to the target type.

$\varepsilon$ can be calculated based on NDVI and land cover type (Sobrino et al., 2001; Van and Owe, 1993). Therefore, $\varepsilon$ provides an emissivity map of the surface with $30 \mathrm{~m}$ resolution. In 137 Eq. (1), $\mathrm{L}_{\lambda}$ is TOA radiance image with $120 \mathrm{~m}$ resolution for TM band 6 and $60 \mathrm{~m}$ resolution 138 for ETM+ band 6. $L_{\mu}, L_{d}$ and $\tau$ are scalars. Therefore, Eq. (1) is also a process of merging $L_{\lambda}$ 
with the $\varepsilon$ map. The resolution of $\mathrm{L}_{\mathrm{T}}$ was set to $30 \mathrm{~m}$ even though $\mathrm{L}_{\mathrm{T}}$ is calculated from the 60 m resolution TM/ETM+ band 6 .

In the final step the radiance is converted to surface temperature using the Landsat-specific estimate of the Planck curve (Chander and Markham, 2003).

\section{Methods}

\subsection{Overall approach}

An overview of the research design is shown in Fig. 2. Sub-pixel ISA is used as an indicator of the degree of impervious surfaces and the urban spatial extent. It indicates the level of urban development. LSMA is used to derive sub-pixel ISA values for urban land cover patterns. The percent ISA is further classified into groups by the range approach and the threshold continuum approach. The main advantage of the range approach over the threshold approach is that the spatial distribution patterns of the urban thermal environment can be analyzed and compared in different urban development density zones. In the range approach, the urban development densities are defined by the ISA threshold values as $10-30 \%$ for low-density; 30-50\% for medium density; and $>50 \%$ for high-density.

To contrast two different methods of discretizing metric scale percent ISA data, the threshold continuum approach is used to reclassify the percent ISA at 4 threshold values set at $>10 \%,>30 \%,>50 \%$ and $>70 \%$ respectively. In the continuum threshold approach, pixels with percent ISA values are also discretized and assigned a value, but unlike the range approach it creates classes of all pixels with $>10 \%$ ISA as class $1,>30 \%$ ISA class $2, \ldots,>70 \%$.

Landscape pattern metrics are then calculated from the discretized percent ISA data to characterize the spatial structure of urban land cover patterns. Lastly, the LST maps from the two Landsat acquisitions are analyzed in relation to landscape structure derived from the discretized percent ISA.

Fig. 2. Flow chart showing the steps for deriving percent ISA, percent ISA discretization, landscape metrics calculation and analysis with LST. 


\subsection{The derivation of urban percent ISA}

Impervious surface is closely related to urban land cover patterns, and percent ISA can be used to map the urban extent. Therefore, the sub-pixel technique of Linear Spectral Mixture Analysis (LSMA) can be used to extract fractional land cover values from TM/ETM+ imagery. The LSMA approach assumes that the reflectance spectrum measured by a sensor is a linear combination of the spectra of all endmembers within the pixel and that the spectral proportions of the endmembers represent proportions of the area covered by distinct features on the ground (Adams, 1995; Mustard and Sunshine, 1999; Mitraka et al., 2012). The spectral reflectance in band $i$ can be described as:

$$
\mathrm{R}_{\mathrm{i}}=\sum_{k=1}^{n} \mathrm{f}_{\mathrm{k}} \mathrm{R}_{\mathrm{ik}}+\varepsilon_{\mathrm{i}}
$$

where $n$ is the number of end members, $f_{k}$ the fraction of end member $k$ within the pixel, $R_{i k}$ the spectral reflectance of end member $\mathrm{k}$ in band $\mathrm{i}$ and $\varepsilon_{\mathrm{i}}$ the residual error for band $\mathrm{i}$. The fractions of one pixel must sum to 1 and all fractions must be greater than or equal to zero. These conditions can be described by:

$$
\begin{aligned}
& \sum_{k=1}^{n} f_{k}=1 \\
& f_{k} \geq 0 \text { for } k=1, \ldots, n .
\end{aligned}
$$

The fractional cover of each urban component is estimated using Eq. (2) and (3).

Endmember selection is a critical step in LSMA for extracting percent ISA. There are various endmember extraction algorithms used to select endmembers prior to spectral unmixing, including Pixel Purity Index (PPI), N-FINDR, Automatic Morphological Endmember Extraction (AMEE), the simplex growing algorithm (SGA) (Plaza et al., 2002; Chang et al. 2006). The PPI method finds the image endmembers automatically and the PPI algorithm works as a simple technique designed to search for a set of vertices of a convex hull in an image cube. In this study, image endmembers identifying spectrally pure pixels were derived by the PPI and the extremes of the image feature space. A Minimum Noise Fraction (MNF) transformation was initially applied to the imagery to reduce inherent noise. In applying the PPI analysis to the MNF output to rank the pixels based on relative purity and 
spectral extremes, the PPI was computed by repeatedly projecting n-dimensional scatterplots on a random unit vector. The algorithm records the extreme pixels in each projection and the total number of times that each pixel was marked as extreme. By setting a PPI threshold, the region of interest (ROI) of pure pixels was determined. Within this ROI, endmember classes were selected by choosing pixels at the edges of the point cloud in three-dimensional scatterplots as pure pixels. All LSMA procedures were undertaken in ENVI 4.5.

In accordance with the VIS model (Ridd, 1995), the urban environment was assumed to consist of four fundamental components: water, vegetation, impervious surfaces and soil. Because the spectral features of water are similar to those of low-albedo impervious areas and the water surfaces in the images were the river flowing through the city, water was masked out from the images. The spectral response of the impervious component in the urban environment varied widely. Two main categories of impervious surface components, bright ISA (such as concrete) and dark ISA (such as asphalt), were respectively assumed as a high-albedo and a low-albedo component (Lu and Weng, 2006). Therefore, four endmembers, vegetation, high-albedo impervious surfaces, low-albedo impervious surfaces and soil, were defined in the study. A constrained least-squares solution was then applied to spectrally unmix the six TM/ETM+ bands into four fraction images. The high-albedo and low-albedo impervious surfaces were added up to an image of total percent ISA. ISA is often biased due to the heterogeneity of urban landscapes and the limitation of remotely sensed data in spectral and spatial resolutions. The high-albedo fraction image also included some soil areas. Bare soil areas are mainly distributed alongside the river; therefore soil does not have a significant effect on the estimation of urban percent ISA.

Using the high-resolution imagery as validation data, the accuracy of percent ISA was assessed by comparing the accumulated fraction estimates in selected test areas with the impervious surface areas extracted from the high resolution aerial photos and the IKONOS image. The acquisition years of the aerial photos and IKONOS image are nearly same year as 220 the acquisition years of TM/ETM+ imagery. The iterative self-organizing data analysis 221 technique algorithm (ISODATA) was used to extract ISA from aerial photos and the 
IKONOS image respectively and further to accumulate the area of ISA in the selected test areas as reference data. This approach was deemed sufficient because the two dates in which the aerial photos and IKONOS image acquired were nearly the same date as those of the TM/ETM+ imagery, in which the land cover type nearly had not changed between the two dates.

\subsection{Percent ISA discretization}

Fractional values of percent ISA have to be modified before landscape metrics can be calculated since these metrics can only be calculated based on a hard classification. Hence, the fractional values were classified into discrete groups using thresholds of percent ISA. The two approaches, namely the range approach and the threshold continuum approach, were used.

The range approach reclassifies pixels based on proportional ranges. Each proportional range has an upper and lower limit. Sporadic, isolated pixels and patches can be found in the results sometimes when the range approach is used. Therefore, the threshold continuum approach was also used as an alternative to the range approach. The threshold continuum approach treats the landscape as a gradually changing gradient and eliminates problems associated with the range approach by aggregating all pixels with values greater than a threshold value. Pixels exceeding a threshold are reclassified in a binary scheme. Percent ISA was also reclassified into discrete maps of ISA presence-absence using the threshold continuum approach. All pixels with ISA proportions greater than or equal to the threshold breakpoints were assigned a value of 1 and included in the landscape metrics calculations, and all other pixels were assigned 0 and excluded from the landscape metrics calculations. In this way, landscape structure can be examined for different degrees of imperviousness.

\subsection{Computation of landscape metrics}

The number of land use/land cover (LULC) categories, their proportions and spatial structure evidently affect LST (Weng et al., 2004; Liu and Weng, 2008). Because percent ISA is an indicator of urban spatial structure and the level of urban development, landscape metrics based on this metric can characterize land cover patterns and their impact on the 
thermal environment better than a 'hard' land cover classification. Five landscape metrics were derived from the discretized percent ISA and used to analyze the landscape patterns and LST in both seasons. The five landscape metrics were generated using the computer program FRAGSTATS (McGarigal et al., 2002). The metrics are briefly introduced below.

Patch density (PD) is a metric of landscape structure. The number of patches per unit area of a specific LULC category measures the spatial heterogeneity of a given landscape. PD for a particular LULC category can serve as an index of landscape fragmentation. The PD of a given LULC type can be derived as:

$$
\mathrm{PD}=N \times 10^{6} / A
$$

where $N=$ total number of patches in the landscape, $A=$ total landscape area $\left(\mathrm{m}^{2}\right)$. PD in eq. (4) is expressed as units per 100 hectares.

The aggregation index (AI) identifies the tendency of spatial aggregation of specific patch types. AI is calculated from an adjacency matrix of pixels, which is indicative of the frequency with which different pairs of patch types (including adjacencies between the same patch types) appear side-by-side in the landscape (McGarigal et al., 2002):

$$
\mathrm{AI}=g_{i j} /\left[\max \left(g_{i j}\right) \times 100\right]
$$

where $g_{i j}=$ number of like adjacencies between pixels of patch type $i$ based on the single-count method, $\max \left(g_{i j}\right)=$ maximum number of like adjacencies .

Cohesion measures the physical connectedness of patches at fractional ISA thresholds and is computed from patch area and perimeter (Schumaker, 1996). Higher cohesion values indicate a more connected landscape and lower values indicate fragmented and less connected, however cohesion will equal zero when the landscape consists of a single patch.

$$
\text { COHESION }=\left\{\left[1-\sum_{j=1}^{N} p_{i j} /\left(\sum_{j=1}^{N} p_{i j}^{*} a_{i j}^{1 / 2}\right)\right] /\left(1-1 / \mathrm{A}^{1 / 2}\right)\right\} * 100
$$

$p_{i j}=$ the perimeter of patch $\mathrm{i}$ of class $j, a_{i j}=$ the area of patch $i$ of class $j, \mathrm{~A}=$ the total number of cells, $\mathrm{N}=$ the number of patches of class $j$. Cohesion values are unit-less and range from 0 to 100.

Landscape Shape Index (LSI) measures shape complexity of patches. It is given as: 
where $\mathrm{P}$ is the total perimeter edges in the landscape and $\mathrm{A}$ is the total area of the landscape.

Perimeter-area fractal dimension index (PAFRAC) is used to measure shape complexity of patch types and provides a measure of human impact on the landscape. It is based on the assumption that natural boundaries have complex shapes, and that as human disturbance increases the PAFRAC decreases, approaching 1. Thus the PAFRAC represents shape complexity representing human-induced disturbance. PAFRAC can be derived as:

PAFRAC $=2 /$

$\left\{\left[N \sum_{i=1}^{m} \sum_{j=1}^{n}\left(\ln p_{i j} \ln a_{i j}\right)-\left(\sum_{i=1}^{m} \sum_{j=1}^{n} \ln p_{i j}\right)\left(\sum_{i=1}^{m} \sum_{j=1}^{n} \ln a_{i j}\right)\right] /\left[\left(N \sum_{i=1}^{m} \sum_{j=1}^{n} \ln _{p_{i j}}^{2}\right)-\sum_{i=1}^{m} \sum_{j=1}^{n} \ln p_{i j}\right]\right\}$

Where $a_{i j}=$ area of the patch $i j, p_{i j}=$ perimeter of the patch $i j, N=$ total number of patches.

\section{Results and discussion}

\subsection{Urban percent ISA results}

Fig. 3 shows the endmember fractions of impervious surface in study area, the fraction values range from 0 to $100 \%$ for two dates, with lowest values in black and highest values in white. The mean root mean square (RMS) over the image is 0.01 , which suggests a good fit of this model. These fractions provide a measure of the physical properties of the urban land cover patterns in the scene at two different dates, thus helping reveal the morphological patterns of urban neighborhoods. The percent ISA covers a continuous range from $0 \%$ to $100 \%$, where the higher percent ISA threshold values capture the more developed land and high-density residential areas. Thus, the ISA proportional ranges can define the urban development densities.

301 Fig. 3. Percent ISA images from LSMA of six TM/ETM+ reflective bands: (a) 1989 and (b) 2001 (Four sample plots delineated with polygons represent test sites for accuracy assessment). 
Fig. 3 shows the spatial patterns of the percent ISA on the two acquisition dates. The changes in ISA over time vary remarkably between the core of the city and its periphery. This suggests that patterns of percent ISA and morphological changes in these areas are primarily between land cover classes and less within classes. On the periphery of the city impervious surfaces have increased because of urban expansion. The urban vegetation in the study area in the winter months is green. Fig. 3 shows that percent ISA of some pixels in urban areas is higher in the summer of 1989 in comparison to spring 2001. Planning in Fuzhou has increasingly included a trend towards ecological urban landscape design, and thus in the more recent image of 2001 a higher vegetation cover is found in the highly developed areas compared to 1989.

In the non-urban areas land cover change has occurred between 1989 and 2001. In some areas, land cover change is taking place at the sub-pixel scale but is not yet detectable at the pixel scale. Thus, a crisp classification would likely result in a misleading conclusion that no change is taking place in some areas of Fuzhou. Fractional cover can be used to quantify the magnitude of change because of its capability to deal with uncertainties resulting from the difficulty in determining a firm threshold value to separate areas of change from those of no change.

\subsection{Accuracy analysis of percent ISA derivation by area}

ISA was extracted from high-resolution air photo/IKONOS data using ISODATA, and was used to assess the accuracy of the percent ISA coarser resolution estimates from Landsat. Four test areas were chosen (Fig. 3) for the accuracy analysis, based on the criterion that the main land cover type had not changed between the aerial photos (acquired in 1988)/IKONOS (acquired in 2000) data and the Landsat TM (acquired in 1989)/ETM+ (acquired in 2001) data. The sites were selected in order to avoid temporal between-class land cover change influencing the accuracy assessment of the endmember-derived impervious surface fraction 330 from the Landsat data using the high-resolution IKONOS/air photo data as surrogate 'ground 331 truth'. Table 1 shows the results of the accuracy assessment of the Landsat-derived percent 332 ISA images. An area accumulation was carried out by multiplying percent ISA with the pixel 333 area of $30 \mathrm{~m} * 30 \mathrm{~m}=900 \mathrm{~m}^{2}$. 
Table 1 Results of accuracy assessment of LSMA percent ISA fractions. Areas measured in $\mathrm{km}^{2}$.

Because of urban expansion and land cover change, the urban area in 2001 is larger than in 1989. The results indicate that there is good agreement between the Landsat-derived ISA fractions and the reference ISA estimates from the airphotos and IKONOS. The four test sites have small total mean differences of ISA when compared to the reference data for both dates (Table 1). The accuracy of impervious surface fractions was slightly lower in 1989. One likely reason for this is that the image quality, the interpretation of the aerial photos and the TM image are less precise than the IKONOS and ETM+ results. Generally, the overall accuracy analysis results are consistent with the individual results per site. In addition, Chen et al. (2010) and van der Meer et al. (2012) have pointed out that if the spectra of endmembers are highly correlated (collinearity or multi-collinearity), the inversion of spectral unmixing becomes unstable and the estimated fractions are sensitive to random error. Because the focus of this study is on urban land cover and thermal patterns, the correlation between endmembers and its impacts on the accuracy of fraction estimation was not analyzed in detail.

\subsection{Percent ISA and LST}

The proportional ranges $0-10 \%, 10-30 \%, 30-50 \%, 50-70 \%$ and $70-100 \%$ were used to reclassify percent ISA into 5 separate groups for indicating the levels of urban development (Fig. 4). The threshold continuum approach was also used to reclassify the sub-pixel data at 4 threshold values set at $>10 \%,>30 \%,>50 \%$ and $>70 \%$ respectively. Reclassifying percent ISA in this manner to generate landscape metrics for each range is suitable for an analysis of urban LST for each range of ISA. The main advantage of this approach over the threshold approach is that the spatial distribution patterns of the urban thermal environment can be analyzed and compared in different urban development density zones. The threshold continuum approach 360 was also used to reclassify the sub-pixel data at 4 threshold values set at $>10 \%,>30 \%,>50 \%$ 361 and $>70 \%$ respectively. The urban development densities were further defined by the ISA 
6

threshold values as $10-30 \%$ for low-density; $30-50 \%$ for medium density; and $>50 \%$ for high-density.

(a)

Fig. 4. Discretized maps of percent ISA in the study area using the range approach: (a) 1989 and (b) 2001.

As illustrated by the ISA maps in Fig. 4, the higher percent ISA threshold values capture the more developed land in the city. The percent ISA analysis captures the spatial variation of the urbanization dynamics and the direction of change (increase, decrease) in both seasons. Table 2 shows the categories of urban percent ISA in the study area. The areal extent of percent ISA > 10\% increased from $254.53 \mathrm{~km}^{2}$ in 1989 to $289.49 \mathrm{~km}^{2}$ in 2001 . The decrease in the category $10-30 \%$ ISA was small. The 30\%-50\% ISA category shows a significant decrease. The largest increase of $87.77 \%$ occurred in the category $>70 \%$ ISA, which means that high density urban development was the dominant mode of urbanization over the 12 year period. The increase of ISA in the categories of $50-70 \%$ ISA and $>70 \%$ ISA was more pronounced than the decrease of ISA in the 30-50\% ISA category. Obviously, these zones appeared in the outskirts of the city by 2001 as urbanization expanded into non-urban areas, especially the $<10 \%$ ISA category.

Table 2 The spatial extent $\left(\mathrm{km}^{2}\right)$ of each category of urban percent ISA in 1989 and 2001 and change in spatial extent between the two periods.

Fig. 5 shows the LST maps for both dates in the study area. Stratified by degree of percent ISA, the mean and standard deviation (SD) of LST for each ISA category derived from either the range approach or the threshold continuum approach are shown in Table 3. 


\section{(a)}

(b)

Fig. 5. Spatial distribution patterns of LST from the TM image acquired on June 15, 1989 (a) and ETM+ image acquired on March 4, 2001 (b).

Table 3 The mean and standard deviation (SD) of LST for each ISA category in 1989 and 2001.

Table 3 shows that the high-density urban areas (percent ISA >50\%, 50\%-70\%, and >70\%) have a higher mean LST exceeding $301 \mathrm{~K}$ for 1989. However, in 2001 the mean LST of these denser areas was nearly the same as that of the lower density urban areas of $>30 \%$ and 30\%-50\% ISA, with temperatures around $289 \mathrm{~K}$. The main reason for this difference is seasonal variation.

There is some homogenization and expansion of high density urban areas over the study region in 2001 compared to 1989. This is further supported by the comparison of the SD of LST for the percent ISA categories. Analyzing the change trends of the SDs of LST for $>30 \%$ and $30 \%-50 \%$ ISA with those for $>50 \%, 50 \%-70 \%$ and $>70 \%$ ISA, the data showed that the SDs of LST for $50 \%-70 \%$ and $>70 \%$ ISA decreased more in 2001 compared to 1989. In the percent ISA categories $50 \%-70 \%$ and $>70 \%$, the SDs of LST are much larger in 1989 compared to 2001, although this difference in SD of LST could also be partly attributed to seasonal fluctuations of LST, as mean LST and its SD in early spring (March 2001) would be expected to be less than in summer (June 1989). It is obvious that the SDs of LST are generally larger for urban areas than those of the areas with percent ISA $<10 \%$, indicating that the urban landscapes would have experienced a wider variation in LST than the natural vegetation areas because of the mix of LULC types. The larger SDs of LST were found to be associated with $>70 \%$ percent ISA (more than $5 \mathrm{~K}$ in summer and $1.8 \mathrm{~K}$ in early spring) 
related to transport infrastructure and industrial land. Residential areas and public facilities are usually included in the 30\%-50\% and 50\%-70\% ISA categories and had a relatively small SD owing to their spatial homogeneity. The SDs of LST were relatively small for the low-density residential areas because the greater homogeneity contributes to lower LST variation in these areas.

In Table 3, the threshold continuum approach was used for partitioning percent ISA into discrete classes. A comparison of the range approach and threshold continuum approach showed differences in both the number of pixels and the distribution of pixels across the ranges. Table 3 also shows that the means and SDs of LST varied for each ISA category between the two approaches. For the range approach, the number of pixels in each of the four ranges was approximately uniform. When pixels are reclassified using the threshold continuum approach, all pixels above the threshold value are cumulative. Therefore, a larger number of pixels are analyzed at each threshold continuum value compared to the range method. The SD of LST at each threshold continuum value is obviously larger than that of the range method for this reason. There is also a continuous gradual decline in the number of pixels as the threshold increases, indicating a progressively changing landscape.

From the analysis above, we infer that the range approach is better suited for an analysis of the specific ranges of land cover with comparatively uniform pixels. Compared to the range approach, the threshold continuum method is more suitable for characterizing the landscape along a continuum of established minimum land cover proportions such as related to the degree of urban ISA expansion. When using the threshold continuum approach, low thresholds usually include a wide variation of land covers and therefore characterize a heterogeneous landscape. By combining these two discretization approaches to analyze LST patterns as in Table 3, we can quantitatively analyze the impact of each percent ISA zone on the whole urban LST and thermal environment.

\subsection{Urban thermal intensity analysis}

The UHI effect is defined as an average value that represents the difference between the mean surface temperature of urban and rural surrounding areas (Sobrino et al., 2012). The 
LST of vegetated surfaces is comparatively low, and these areas are usually in rural areas with percent ISA $<10 \%$. Here, we defined the UHI intensity as the difference of the urban area with higher LST and the mean LST value of the area with percent ISA $<10 \%$. The spatial extent of the high intensity area covered by the aggregated cluster of urban pixels whose LST is higher than the rural LST can be obtained by a predefined threshold value.

Fig. 6 shows the frequency of the urban thermal intensity occurrences between the urban and suburban area of Fuzhou in 1989 and 2001 as histograms, in which an LST difference >4 K was defined as the threshold value. Fig. 6 was obtained from the difference between the LST inside the urban area and the non-urban area with percent ISA $<10 \%$. It is clear that (1) although the trends of the intensity occurrences were similar for both dates, the differences of the maximum LST value peaked at $11 \mathrm{~K}$ in 1989 and at $9 \mathrm{~K}$ in 2001 because of seasonal variation; (2) the statistics of the thermal intensity are also influenced by the spatial resolution of LST. In this study, the spatial resolution of the LST maps was $30 \mathrm{~m}$. In future, there is a need to analyze the scaling properties of the urban thermal intensity.

Fig. 6. Histogram of urban thermal intensity in Fuzhou in 1989 and 2001.

Fig. 6 shows that the frequency of the pixels $\geq 4 \mathrm{~K}$ varied greatly between both dates because of seasonal variation, especially in the zone of 5-8 K. An analysis with discretized percent ISA in Fig. 4 and LST in Fig. 5 shows that the zones with LST differences of 5-7 K were mainly in the high density development areas (>50\% ISA). The land cover categories in these zones were usually the urban impervious surfaces such as buildings, streets etc. predominantly made of concrete, stone, and metal. Those zones with LST differences $>7 \mathrm{~K}$ in 2001 and $>8 \mathrm{~K}$ in 1989 were mainly some CBD areas, some roads, industrial land, and bare soil areas. Therefore, a quantitative analysis of the spatial distribution patterns of the thermal intensity and percent ISA is significant for urban planning and ecological construction. As urbanization occurred, these zones have appeared in the outskirts of the city and are visible in the 2001 imagery. However, Fig. 6 shows that the spatial extent of the urban thermal intensity 
was larger and its values were higher in the summer of 1989 than that in the early spring of 2001 due to seasonal influences.

\subsection{ISA pattern change analysis using landscape metrics}

The landscape metric results for the range and the threshold continuum approach for discretization show different patterns (Table 4 and 5).

Table 4 Landscape metric values based on range approach for both dates.

Table 5 Landscape metric values based on threshold continuum approach for both dates.

Table 4 shows that the change trends of PD in different ISA categories were similar between 1989 and 2001. The values increased from 1989 to 2001 because urban expansion led to higher patch density, but the values in the 30\%-50\% ISA class span a larger range (13.39-26.56) because PD changes more extensively. This means that the spatial heterogeneity of the impervious surface components in the landscape has increased because of urbanization. In the 10\%-30\% ISA class, the PD values spanned a relatively small range.

LSI and PAFRAC in Table 4 also showed the same trend as PD, increasing in all four ISA zones from 1989 to 2001, and the values of PAFRAC showed a slight variation. It is noticeable that the LSI and PAFRAC show more variability in the 30\%-50\% and 50\%-70\% ISA categories comparatively. In the urbanization process, the structure of the urban landscape was quite complex and the diversity of landscape elements was high. The ISA patches in the urbanized parts of the study area became increasingly fragmented and less connected over time, leading to increasing urban landscape complexity. Therefore, PD, LSI and PAFRAC all increased as the impervious urban areas expanded. The LSI increased in all the four ISA zones of Table 4, showing that the landscape structure became more irregular and complex between the two dates, especially in the last three ISA zones. The total patch edge length in relation to area as expressed in the LSI increased, meaning a higher degree of 
urban landscape fragmentation. The diversity of landscape components in four ISA zones is increasing with the enhancement of the urban growth preference from 1989 to 2001, but landscape geometrical complexity and patch fragmentation have different trends of change under different urban development modes.

Unlike PD, LSI and PAFRAC, the values of AI in Table 4 decreased from 1989 to 2001 as percent ISA increased. AI decreases if the amount of adjacencies of patches of the same class declines over time. This means that spatial aggregations of ISA decreased as the urban expansion resulted in higher fragmentation of discretized ISA patches in the four ISA zones. Urban landscape patterns in the three zones were generally more complex in 2001 than in 1989, which can be explained by the fact that there was more vegetation cover interspersed within the developed areas in 2001 in comparison to 1989. In the 30\%-50\% and 50\%-70\% ISA zones, the values of AI decreased more than other ISA zones from 1989 to 2001.

In Table 4, the COHESION metric decreased in the three zones with less than 70\% ISA but slightly increased in the $>70 \%$ ISA zone. In Table 2 , the areas of $50 \%-70 \%$ and $>70 \%$ ISA significantly increased from 1989 to 2001 and urban expansion occurred more in these two zones than in any other. In Table 4, the values of metrics in the 30\%-50\% and 50\%-70\% ISA zones generally exhibited larger variation. This is indicative of the complexity or heterogeneity of landscapes in the two zones because of the urban landscape patterns change. Urban expansion and the change of landscape patterns influenced the density, aggregation, connectedness, shape and perimeter-area fractal dimensions of ISA patches in different urban developed areas, especially in the 30\%-50\% and 50\%-70\% ISA zones.

The two percent ISA discretization methods had a differential effect on the landscape metrics (Table 4 and 5). In all five metrics tested in Table 4, the values of the range discretization vary relatively little across the percent ISA ranges. In contrast, the values of the threshold continuum approach (Table 5) changed significantly across different thresholds. We observed relatively large change across percent ISA thresholds, while for the threshold continuum approach we also uncovered considerable fluctuations in the results. Generally, the change trends of landscape metrics between two dates in Table 5 are similar to those in Table 
4. However, the results show that landscape metrics results can vary significantly across the landscape depending on fractional cover values. A comparative interpretation of Table 4 and 5 illustrates the impact of percent ISA on urban landscape structure. This is useful for identifying those ISA proportions that lead to the greatest changes in urban landscape structure and the impact of spatial structural patterns on the thermal environment.

\subsection{Pattern analysis of LST and landscape metrics for different seasons}

Landscape patches in a region are linked to distinct properties of the thermal environment. Fig. 7 depicts plots of mean LST and landscape patterns for different percent ISA zones in Fuzhou for both years. The percent ISA zonal distribution patterns are characterized with the structural landscape metrics and LST. Besides LULC, the season has an influence on the LST distribution pattern. LST in 1989 showed higher variability than in 2001 due to the seasonal effect. There are similar trends in landscape metrics in four percent ISA categories between the two dates, however, the landscape metrics in 2001 show a larger variation. The trends indicate that the $10 \%-30 \%$ ISA zones exhibit the lowest landscape metric and LST values. The metrics span a larger range in the $10 \%-30 \%$ to $30 \%-50 \%$ ISA zones. Especially for LSI, the metric increased to maximum values in ISA zone 30\%-50\%, and then decreased sharply as the LST increased. This is indicative of the shape change of ISA patches, and the greater complexity or heterogeneity of landscapes in medium and high urban development densities because urban expansion resulted not only in an increase in absolute ISA extent but also in different urban landscape structures.

In Fig. $7 \mathrm{a}$ and $\mathrm{b}$, the rates of increase of LST were lower than those of AI and COHESION, especially in the high density urban area. For example, for the $30 \%-50 \%$; $50 \%-70 \%$ and $>70 \%$ ISA categories, mean LST increased from $300.3 \mathrm{~K}$ to $301.1 \mathrm{~K}$ and to 302.6 $\mathrm{K}$ in 1989 ; 287.6 $\mathrm{K}$ to $288.4 \mathrm{~K}$ and to $289.5 \mathrm{~K}$ in 2001, respectively. However, COHESION increased from 93.77 to 95.43 and to 98.03 in 1989, and 77.2 to 89.51 and to 55299.12 in 2001. In medium and high density urban areas, AI and COHESION had positive 553 relationships with LST, and LSI had a negative relationship with LST. The implication of this 
finding is that a greater degree of adjacency of patches with the same degree of ISA tends to coincide with a more pronounced UHI effect.

Fig. 7. The 1989 and 2001 landscape metrics and mean LST for each percent ISA category in urban areas.

Quantifying the spatial distribution of ISA patterns with landscape metrics generated from percent ISA and LST over time can indicate the process of urban expansion and its impacts on the thermal environment. This analysis can also provide knowledge for climate change adaptation policies in cities.

\section{Conclusions}

Land use change resulted from urbanization leads to changing landscape patterns and thermal properties. Urban structures are amongst the most complex ones on the Earth's surface (Bechtel and Daneke, 2012; Bechtel, 2012). In this paper, sub-pixel ISA was derived from Landsat data by LSMA and its accuracy assessed with high spatial resolution IKONOS imagery and aerial photographs.

A new method for deriving landscape metrics from percent ISA by discretizing soft classifications of percent ISA using the range approach and the threshold continuum approach over heterogeneous urban areas is presented. The characteristics of the landscape and LST patterns in Fuzhou are explored for the two main seasons using an interpretation of landscape pattern metrics from FRAGSTATS. The information provided by quantifying the relationships between ISA and landscape metrics with LST provided a perspective on the understanding of urban morphology and the urban thermal environment going beyond conventional urban remote sensing studies. Although the Landsat data had only one thermal channel which limited the achievable accuracy of the LST retrieval, it was possible to analyze 580 the urban thermal characteristics. The results provide new knowledge on the climate 
adaptation potential of specific spatial urban landscape patterns of impervious surfaces in cities.

The main results of this research have shown that:

(i) In addition to the absolute amount of impervious surface area, the spatial structural arrangement of such surfaces matters in determining urban land surface temperature, at least in some cities such as Fuzhou.

(ii) The range and continuum threshold approach are a useful framework for understanding the dynamics of urban thermal environments. A comparison of the range and continuum threshold approach shows that ISA impacts on the urban thermal environment. If the percent ISA is to be derived more accurately, the results of the proposed method may be improved.

(iii) In the city of Fuzhou, urban expansion and the change of landscape patterns influenced the density, aggregation, connectedness, shape and perimeter-area fractal dimensions of ISA patches. In medium and high density urban areas, AI and COHESION generated from discrete percent ISA are shown to have positive relationships with LST, and LSI has a negative relationship with LST.

There are several areas for future work arising from this study.

(i) Landscape metrics are sensitive to the discrete percent ISA zones. Future work needs to analyze percent ISA rates of change at various thresholds to determine if there are significant factors operating in the landscape at specific land cover proportions and whether optimal and critical thresholds for landscape characterization can be identified;

(ii) Multi-temporal studies of the thermal environment of a single city that has obvious variations of temperature patterns over four seasons are needed. In addition, comparisons of spatial-temporal patterns of LST and landscape metrics for cities over four seasons would be useful to examine the transferability of our findings to other climate zones;

(iii) Urban landscape patterns were distinguished by percent ISA in this study. In future, local micro-climatic zones such as urban core, urban dense, community area, industrial area, 
and so on can be combined with different percent ISA categories to analyze the urban thermal environment more accurately.

\section{References}

Adams, J. B., Sabol, D. E., Kapos, V., Filho, R. A., Roberts, D. A., Smith, M. O., et al., 1995. Classification of multispectral images based on fractions of endmembers: Application to land cover change in the Brazilian Amazon. Remote Sensing of Environment 52, 137-154.

Amiri, R., Weng, Q., Alimohammadi, A., Alavipanah, S. K., 2009. The spatial-temporal dynamics of land surface temperatures in relation to fractional vegetation cover and land use/cover in the Tabriz urban area, Iran. Remote Sensing of Environment 113, 2606-2617.

Arnold, C. L. Jr., Gibbons, C. J., 1996. Impervious surface coverage the emergence of a key environmental indicator. Journal of the American Planning Association 62, 243-258.

Barsi, J. A., Schott, J. R., Palluconi, F. D., Hook, S. J., 2005. Validation of a web-based atmospheric correction tool for single thermal band instruments. Proceedings, SPIE, Bellingham, WA.

Bechtel, B. Daneke, C., 2012. Classification of local climate zones based on multiple earth observation data. IEEE Transactions on Geoscience and Remote Sensing 5, 1191-1202.

626 Bechtel, B., 2012. Robustness of annual cycle parameters to characterize the urban thermal 627 landscapes. IEEE Geoscience and Remote Sensing letters 9, 876-880.

628 Chander, G., Markham, B., 2003. Revised Landsat-5 TM radiometric calibration procedures and post calibration dynamic ranges. IEEE Transactions on Geoscience and Remote Sensing 41, 2674-2677.

631 Chang, C., Wu, C., Liu, W., Ouyang, Y., 2006. A new growing method for simplex-based 632 endmember extraction algorithm," IEEE Transactions on Geoscience and Remote Sensing 633 44(10), 2804-2819.

634 Chen, X. L., Zhao, M. Z., Li, P. X., Yin, Z. Y., 2006. Remote sensing image-based analysis of 635 the relationship between urban heat island and land use/cover changes. Remote Sensing of 636 Environment 104, 133-146. 
Chen, X., Chen, J., Jia, X. \& Wu, J., 2010. Impact of collinearity on linear and nonlinear spectral mixture analysis. In: BENEDIKTSSON, J. A. (ed.) 2nd Workshop on Hyperspectral Image and Signal Processing (WHISPERS): Evolution in remote sensing. Reykjavik, Iceland: IEEE.

641 Deng, 642 spectral unmixing and thermal mixing approach 23, 155-164.

Frazier, A. E., Wang, L., 2011. Characterizing spatial patterns of invasive species using sub-pixel classifications. Remote Sensing of Environment 115, 1997-2007.

Gallo, K. P., Owen, T. W., 1999. Satellite based adjustments for the urban heat island temperature bias. Journal of Applied Meteorology 38, 806-813.

Gustafson, E. J., 1998. Quantifying landscape spatial pattern: What is the state of the art?. Ecosystems 1, 143-156.

Imhoff, M. L., Zhang, P., Wolfe, R. E., Bounoua, L., 2010. Remote sensing of the urban heat island effect across biomes in the continental USA. Remote Sensing of Environment 114, 504-513.

Kato, S., Yamaguchi, Y., 2005. Analysis of urban heat-island effect using ASTER and ETM+ data: Separation of anthropogenic heat discharge and natural heat radiation from sensible heat flux. Remote Sensing of Environment 99, 44-54.

Li, J., Song, C., Cao, L., et al., 2011. Impacts of landscape structure on surface urban heat islands: A case study of Shanghai, China. Remote Sensing of Environment, 115, 3249-3263. Liu, H., Weng, Q., 2008. Seasonal variations in the relationship between landscape pattern and land surface temperature in Indianapolis, USA. Environmental Monitoring and Assessment 144, 199-219.

Lo, C. P., Quattrochi, D. A., Luvall, J. C., 1997. Application of high resolution thermal infrared remote sensing and GIS to assess the urban heat island effect. International Journal of Remote Sensing 18, 287-304.

Lu, D., Weng, Q., 2006. Use of impervious surface in urban land-use classification. Remote Sensing of Environment 102, 146-160. 
Maimaitiyiming, M., Ghulam, A., Tiyip, T., et al., 2014. Effects of green space spatial pattern on land surface temperature: Implications for sustainable urban planning and climate change adaptation. ISPRS Journal of Photogrammetry and Remote Sensing 89, 59-66.

McGarigal, K., Cushman, S. A., Neel, M. C., Ene, E., 2002. FRAGSTATS: Spatial Pattern Analysis Program for Categorical Maps. Computer software program produced by the authors 670 at the University of Massachusetts, Amherst. Available at the following web site: 671 www.umass.edu/landeco/research/fragstats/fragstats.html.

672 Michishita, R., Jiang, Z., Xu, B., 2012. Monitoring two decades of urbanization in the Poyang 673 Lake area, China through spectral unmixing. Remote Sensing of Environment 117, 3-18.

674 Mitraka, Z., Chrysoulakis, N., Kamarianakis, Y., Partsinevelos, P., Tsouchlaraki, A., 2012. 675 Improving the estimation of urban surface emissivity based on sub-pixel classification of high 676 resolution satellite imagery. Remote Sensing of Environment 117, 125-134.

677 Mustard, J. F., Sunshine, J. M., 1999. Spectral analysis for earth science: Investigations using 678 remote sensing data. In A. N. Rencz (Ed.), Remote sensing for the earth sciences: Manual of remote sensing, vol. 3 (3rd ed.), John Wiley \& Sons Inc., New York, pp. 251-307.

680 Owen, T. W., Carlson, T. N., Gillies, R. R., 1998. An assessment of satellite remotely sensed 681 land cover parameters in quantitatively describing the climatic effect of urbanization. 682 International Journal of Remote Sensing 19, 1663-1681.

683 Plaza, Martínez, P., Gualtieri, J. A., Pérez, M. R., 2002. Automated identification of 684 endmembers from hyperspectral data using mathematical morphology. Image and Signal 685 Processing for Remote Sensing VII, Proceedings of SPIE 4541, 278-287.

686 Price, J. C., 1990. Using spatial context in satellite data to infer regional scale 687 evapotranspiration. IEEE Transactions on Geoscience and Remote Sensing 28, 940-948.

688 Pu, R., Gong, P., Ryo, M., Todashi, S., 2006. Assessment of multi-resolution and multi-sensor 689 data for urban surface temperature retrieval. Remote Sensing of Environment 104, 211-225. 690 Rashed, T., 2008. Remote sensing of within-class change in urban neighborhood structures. 691 Computers, Environment and Urban Systems 32, 343-354. 
6
Ridd, M. K., 1995. Exploring a V-I-S (vegetation-impervious surface-soil) model for urban ecosystem analysis through remote sensing: comparative anatomy for cities. International Journal of Remote Sensing 16, 2165-2185.

695 Riitters, K. H., O’Neill, R. V., Hunsaker, C. T., et al., 1995. A factor analysis of landscape 696 pattern and structure metrics. Landscape Ecology 10, 23-39.

697 Schroeder, T. A., Cohen, W. B., Song, C. H., Canty, M. J., Yang, Z. Q., 2006. Radiometric 698 correction of multi-temporal Landsat data for characterization of early successional forest 699 patterns in western Oregon. Remote Sensing of Environment 103, 16-26.

700 Berk, A., Anderson, G. P., Acharya, P. K., et al., 1999. MODTRAN4 User's Manual, Air 701 Force Research Laborary, North Andover, MA, USA, pp. 10-35.

Schumaker, N., 1996. Using landscape indices to predict habitat connectivity. Ecology 77, $1210-1225$.

704 Smith, M. O., Ustin, S. L., Adams, J. B., Gillespie, A. R., 1990. Vegetation in deserts: I. A 705 regional measure of abundance from multispectral images. Remote Sensing of Environment $706 \quad 31,1-26$.

707 Sobrino, J. A., Oltra-Carrió, R., Sòria, G., Bianchi, R., Paganini, M., 2012. Impact of spatial 708 resolution and satellite overpass time on evaluation of the surface urban heat island effects. 709 Remote Sensing of Environment 117, 50-56.

710 Sobrino, J. A., Raissouni, N., Li, Z. L., 2001. A comparative study of land surface emissivity 711 retrieval from NOAA data. Remote Sensing of Environment 75, 256-266.

712 Van De Grienzd, A. A., Owe, M., 1993. On the relationship between thermal emissivity and 713 the normalized difference vegetation index for nature surfaces. International Journal of 714 Remote Sensing 14, 1119-1131.

715 Van Der Meer, F. D. \& Jia, X. P., 2012. Collinearity and orthogonality of endmembers in 716 linear spectral unmixing. International Journal of Applied Earth Observation and 717 Geoinformation 18, 491-503.

718 Voogt, J. A., Oke, T. R., 2003. Thermal remote sensing of urban climates. Remote Sensing of 719 Environment 86, 370-384. 
Wan, Z., Dozier, J., 1996. A generalized split-window algorithm for retrieving land-surface temperature from space. IEEE Transactions on Geoscience and Remote Sensing 34, 892-905. Weng, Q., Lu D., Schubring J., 2004. Estimation of land surface temperature-vegetation abundance relationship for urban heat island studies. Remote Sensing of Environment 89, 467-483.

Xian, G., Crane, M., 2006. An analysis of urban thermal characteristics and associated land cover in Tampa Bay and Las Vegas using Landsat satellite data. Remote Sensing of 727 Environment 104, 147-156.

728 Yuan, F., Bauer, M. E., 2007. Comparison of impervious surface area and normalized 729 difference vegetation index as indicators of surface urban heat island effects in Landsat imagery. Remote Sensing of Environment 106, 375-386.

Yue, W., Xu, J., Tan, W., Xu, L., 2007. The relationship between land surface temperature and NDVI with remote sensing: application to Shanghai Landsat 7 ETM+ data. International Journal of Remote Sensing 28, 3205-3226.

Zhang, Y., Odeh, I., Han, C., 2009. Bi-temporal characterization of land surface temperature in relation to impervious surface area, NDVI and NDBI, using a sub-pixel image analysis. International Journal of Applied Earth Observation and Geoinformation 11, 256-264.

Zhang, Y., Odeh, I., Ramadan, E., 2013. Assessment of land surface temperature in relation to landscape metrics and fractional vegetation cover in an urban/peri-urban region using Landsat data. International Journal of Remote Sensing, 34, 168-189.

Zhang, Y., Balzter, H., Wu, X., 2013. Spatial-temporal patterns of urban anthropogenic heat discharge in Fuzhou, China, observed from sensible heat flux using Landsat TM/ETM+ data. International Journal of Remote Sensing, 34, 1459-1477.

Zhou, D., Zhao, S., Liu, S., Zhang, L., Zhu, C., 2014. Surface urban heat island in China's 32 major cities: Spatial patterns and drivers. Remote Sensing of Environment 152, 51-61. 
Figure 1 Location of the study area showing the Landsat 7 ETM+ image.

Figure 2 Flow chart showing the steps for deriving percent ISA, percent ISA discretization, landscape metrics calculation and analysis with LST.

Figure 3 Percent ISA images from LSMA of six TM/ETM+ reflective bands: (a) 1989 and (b) 2001 (Four sample plots delineated with polygons represent test sites for accuracy assessment).

Figure 4 Discretized maps of percent ISA in the study area using the range approach: (a) 1989 and (b) 2001.

Figure 5 Spatial distribution patterns of LST from the TM image acquired on June 15, 1989 (a) and ETM+ image acquired on March 4, 2001 (b).

758 Figure 6 Histogram of urban thermal intensity in Fuzhou in 1989 and 2001.

Figure 7 The 1989 and 2001 landscape metrics and mean LST for each percent ISA category in urban areas.

List of Table Captions

Table 1 Results of accuracy assessment of LSMA percent ISA fractions. Areas measured in $\mathrm{km}^{2}$.

Table 2 The spatial extent $\left(\mathrm{km}^{2}\right)$ of each category of urban percent ISA in 1989 and 2001 and change in spatial extent between the two periods.

Table 3 The mean and standard deviation (SD) of LST for each imperviousness category in 1989 and 2001.

768 Table 4 Landscape metric values based on range approach for both dates.

769 Table 5 Landscape metric values based on threshold continuum approach for both dates. 


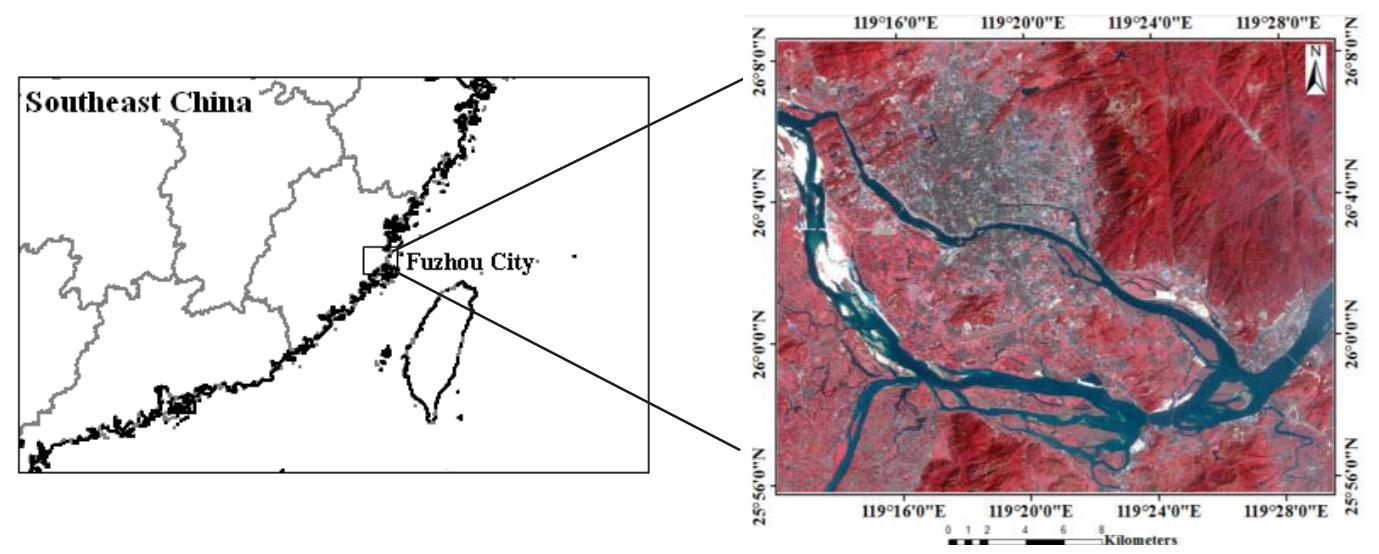

Fig. 1. Location of the study area showing the Landsat 7 ETM+ image ( $\mathrm{Red}=$ band 4, Green $=$ band 3 , Blue $=$ band 2).

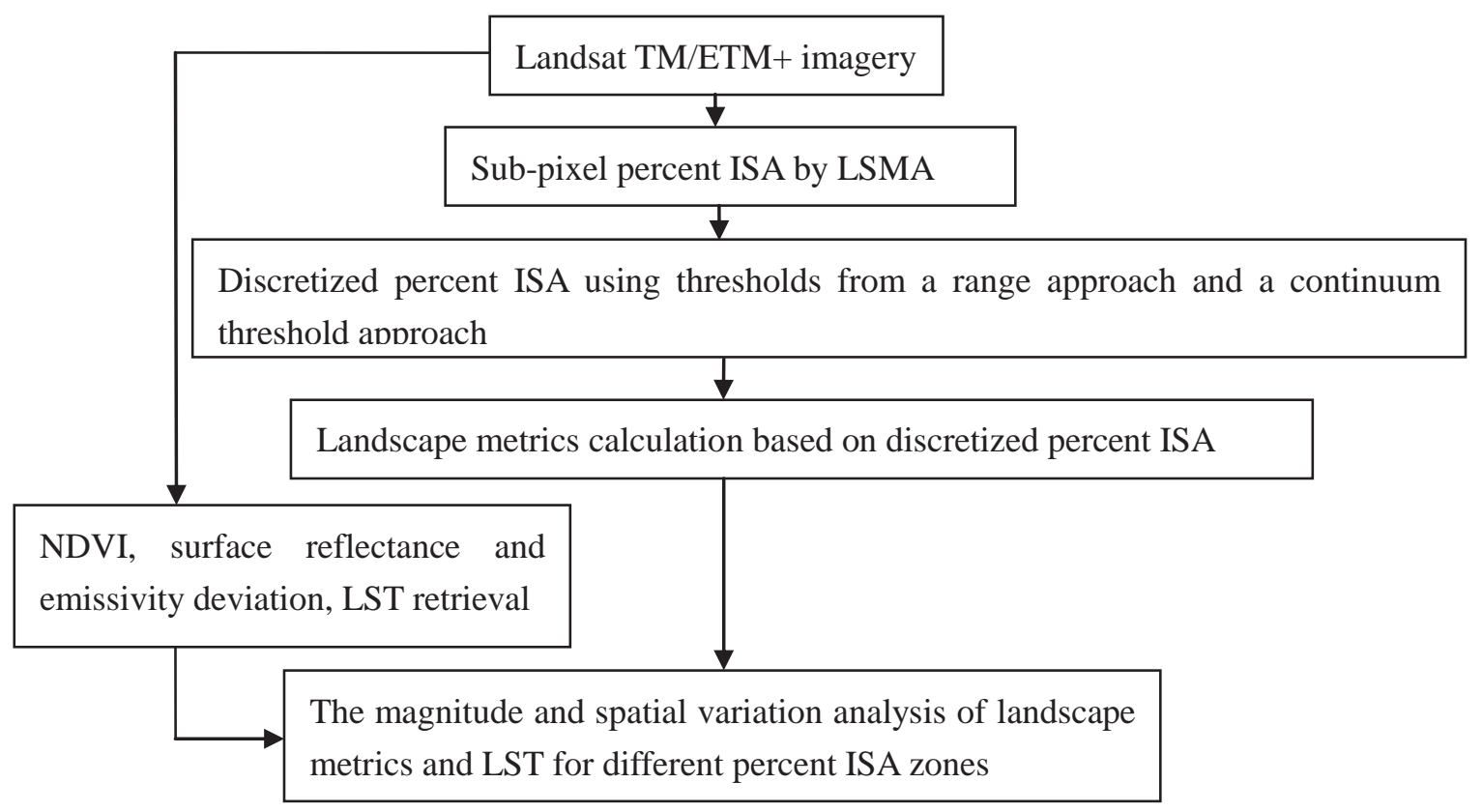

Fig. 2. Flow chart showing the steps for deriving percent ISA, percent ISA discretization, landscape metrics calculation and analysis with LST.

(a)

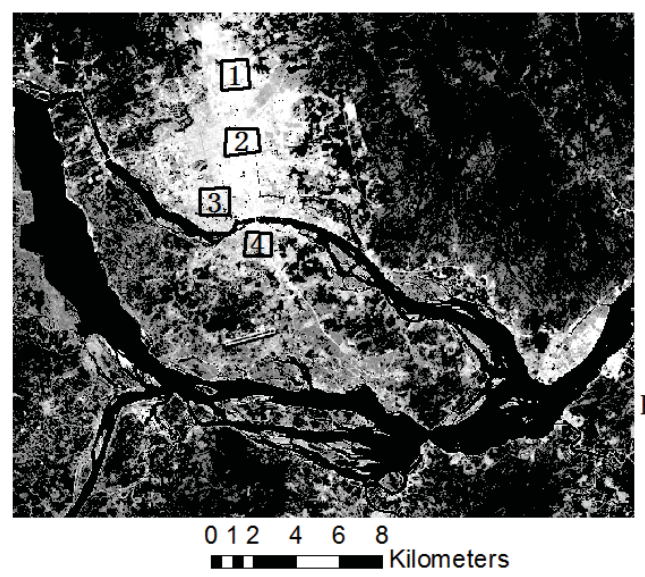

(b)

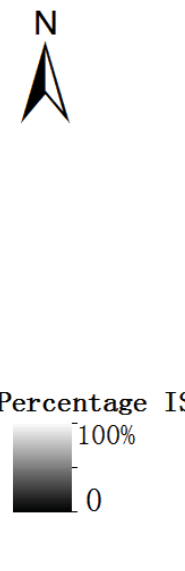

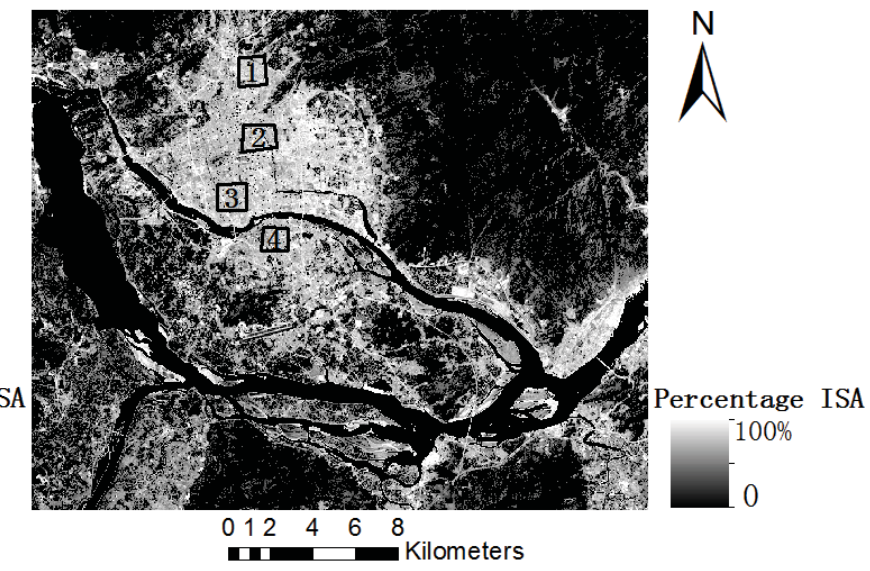

Fig. 3. Percent ISA images from LSMA of six TM/ETM+ reflective bands: (a) 1989 and (b) 2001 (Four 
sample plots delineated with polygons represent test sites for accuracy assessment).

(a)

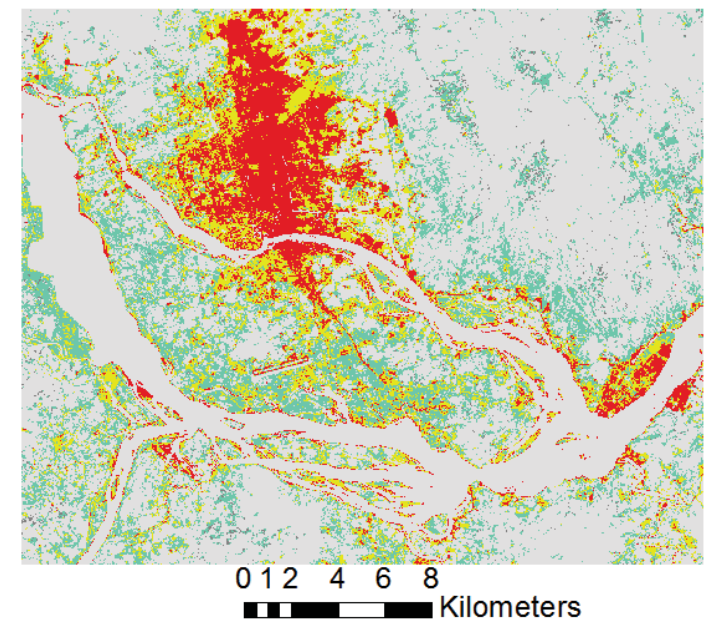

(b)

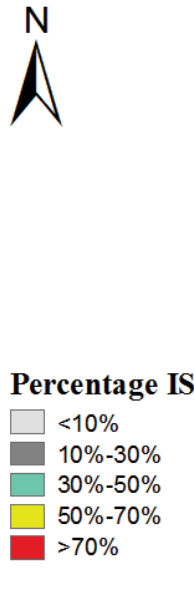

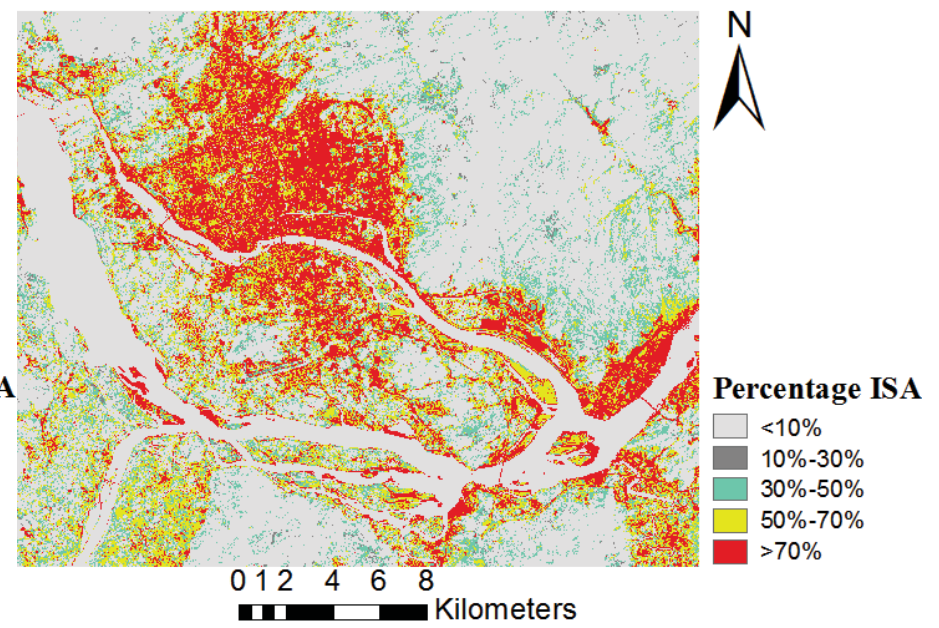

Fig. 4. Discretized maps of percent ISA in the study area using the range approach: (a) 1989 and (b) 2001.

(a)

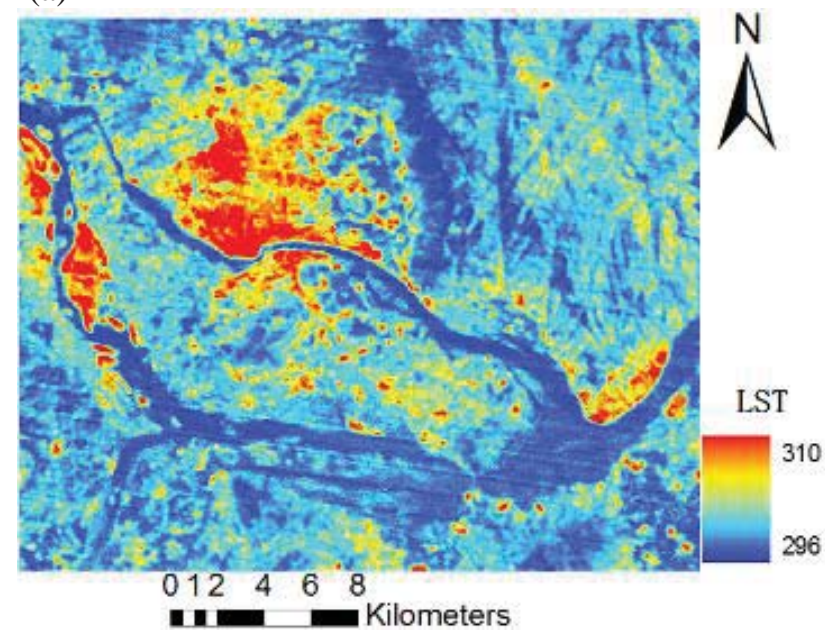

(b)

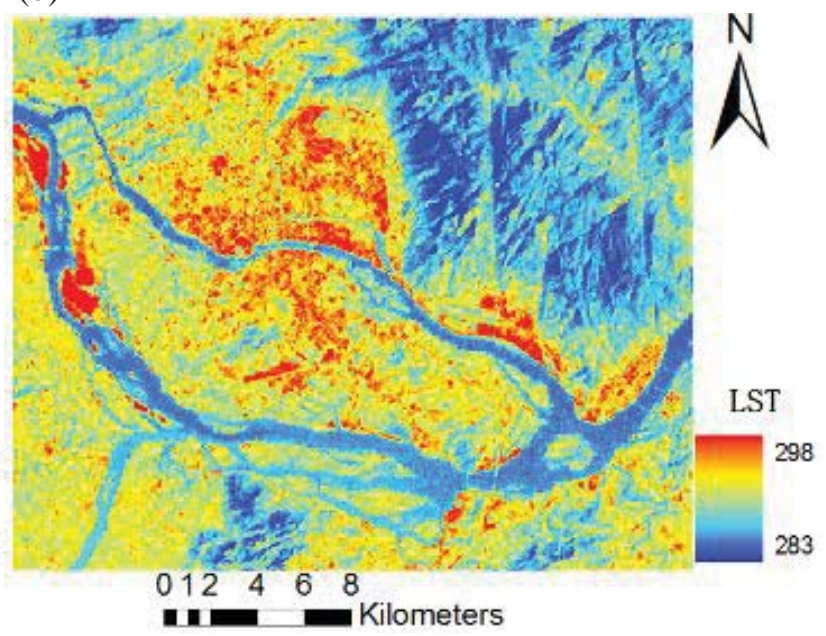

Fig. 5. Spatial distribution patterns of LST from the TM image acquired on June 15, 1989 (a) and ETM+ image acquired on March 4, 2001 (b) (local time).

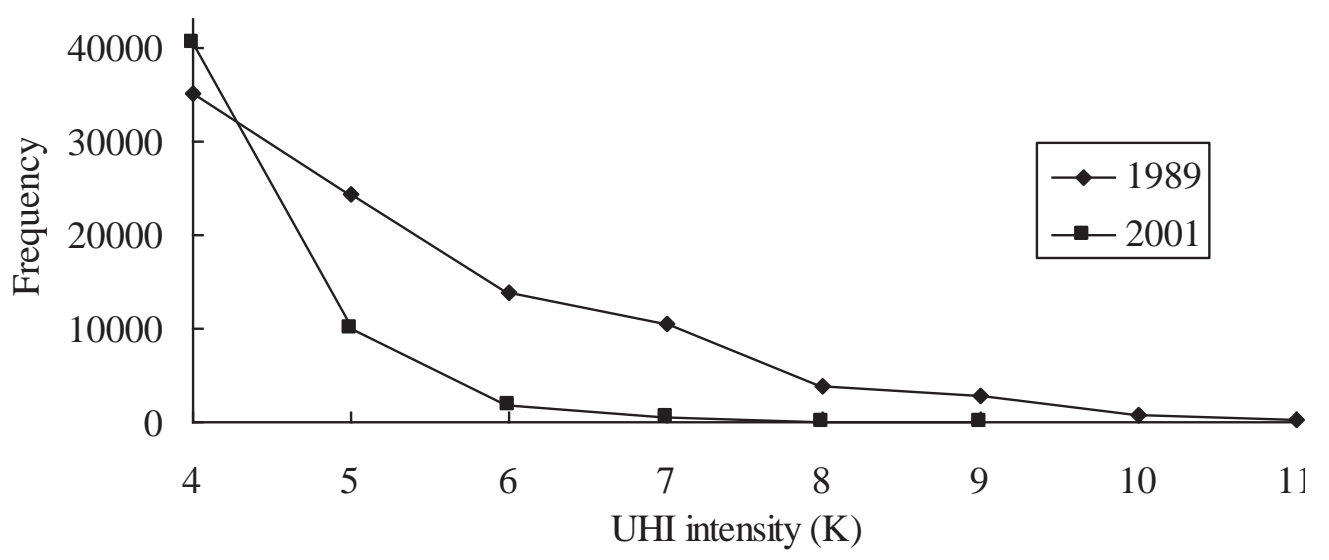

Fig. 6. Histogram of urban thermal intensity in Fuzhou in 1989 and 2001. 
(a)

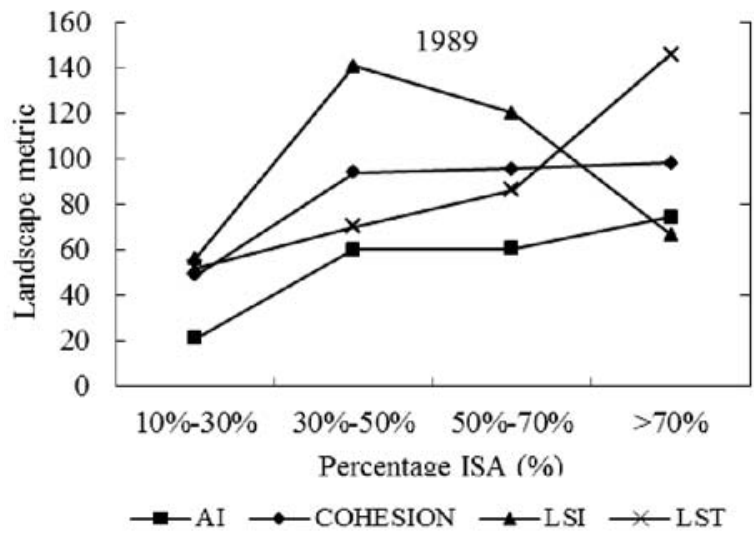

(b)

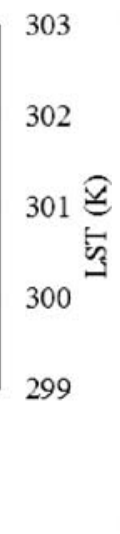

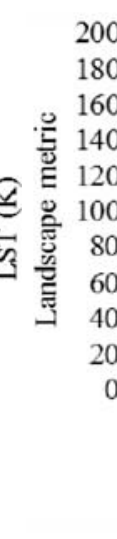

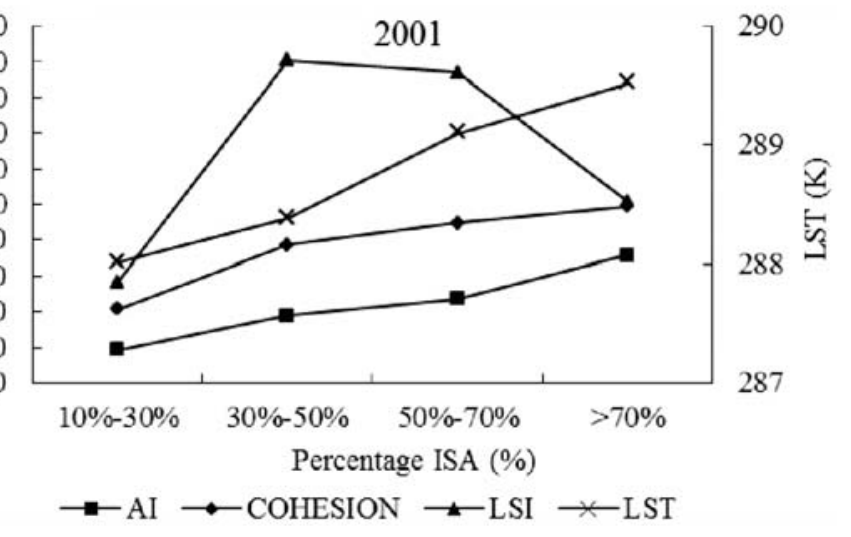

Fig. 7. The 1989 and 2001 landscape metrics and mean LST for each percent ISA category in urban areas. 
Table 1 Results of accuracy assessment of LSMA percent ISA fractions. Areas measured in $\mathrm{km}^{2}$.

\begin{tabular}{ccccccc}
\hline ISA sites & $\begin{array}{c}\text { Area of ISA from } \\
\text { accumulated fraction } \\
\text { from TM image in 1989 }\end{array}$ & $\begin{array}{c}\text { ISA area of reference } \\
\text { data from aerial } \\
\text { photos in 1988 }\end{array}$ & $\begin{array}{c}\text { Average } \\
\text { difference }\end{array}$ & $\begin{array}{c}\text { Area of ISA from } \\
\text { accumulated fraction from } \\
\text { ETM+ image in 2001 }\end{array}$ & $\begin{array}{c}\text { ISA area of reference Average } \\
\text { image in 2000 }\end{array}$ \\
\hline Site 1 & 1.570 & 1.662 & $5.86 \%$ & 1.675 & 1.587 & $5.25 \%$ \\
Site 2 & 1.712 & 1.865 & $8.94 \%$ & 1.683 & 1.766 & $4.93 \%$ \\
Site 3 & 1.224 & 1.396 & $14.05 \%$ & 1.297 & 1.467 & $13.11 \%$ \\
Site 4 & 0.963 & 1.034 & $7.37 \%$ & 1.169 & 1.321 & $13.00 \%$ \\
Total & 5.469 & 5.957 & $8.92 \%$ & 5.824 & 6.141 & $5.44 \%$ \\
\hline
\end{tabular}

Table 2 The spatial extent $\left(\mathrm{km}^{2}\right)$ of each category of urban percent ISA in 1989 and 2001 and change in spatial extent between the two periods.

\begin{tabular}{cccccc}
\hline Year/percent ISA & $10-30 \%$ ISA & $30-50 \%$ ISA & $50-70 \%$ ISA & $>70 \%$ ISA & Total urban area \\
\hline $1989\left(\mathrm{~km}^{2}\right)$ & 4.57 & 109.58 & 81.43 & 58.95 & 254.53 \\
2001 $\left(\mathrm{km}^{2}\right)$ & 4.42 & 76.09 & 98.29 & 110.69 & 289.49 \\
Changes $\left(\mathrm{km}^{2}\right)$ & -0.15 & -33.49 & 16.87 & 51.74 & \\
Percent change & $-3.28 \%$ & $-30.56 \%$ & $20.72 \%$ & $87.77 \%$ & \\
\hline
\end{tabular}

Table 3 The mean and standard deviation (SD) of LST for each imperviousness category in 1989 and 2001.

\begin{tabular}{cccccccc}
\hline percent ISA & $>10 \%$ & $10 \%-30 \%$ & $>30 \%$ & $30 \%-50 \%$ & $>50 \%$ & $50 \%-70 \%$ & $>70 \%$ \\
\hline Mean 1989 LST (K) & 301.09 & 299.63 & 301.1 & 300.07 & 301.78 & 301.15 & 302.64 \\
SD of 1989 of LST (K) & 4.03 & 1.02 & 4.07 & 1.27 & 5.06 & 4.08 & 5.11 \\
Mean 2001 LST (K) & 289.02 & 287.78 & 289.03 & 288.27 & 289.3 & 289.00 & 289.52 \\
SD of 2001 of LST (K) & 1.92 & 1.79 & 1.93 & 1.86 & 1.65 & 1.53 & 1.82 \\
\hline
\end{tabular}

Table 4 Landscape metric values based on range approach for both dates.

\begin{tabular}{cccccccccc}
\hline Landscape metrics/ Percent ISA & \multicolumn{2}{c}{$10 \%-30 \%$} & \multicolumn{2}{c}{$30 \%-50 \%$} & \multicolumn{2}{c}{$50 \%-70 \%$} & \multicolumn{2}{c}{$>70 \%$} \\
\hline & 1989 & 2001 & 1989 & 2001 & 1989 & 2001 & 1989 & 2001 \\
\cline { 2 - 10 } PD & 3.67 & 3.89 & 13.39 & 26.56 & 9.01 & 17.47 & 5.90 & 8.24 \\
AI & 20.96 & 18.65 & 59.91 & 37.68 & 60.29 & 47.48 & 74.35 & 71.68 \\
COHESION & 48.72 & 41.35 & 93.77 & 77.2 & 95.43 & 89.51 & 98.03 & 99.12 \\
LSI & 56.29 & 56.84 & 140.47 & 180.84 & 119.95 & 174.02 & 66.37 & 101.81 \\
PAFRAC & 1.53 & 1.54 & 1.55 & 1.61 & 1.55 & 1.63 & 1.50 & 1.50 \\
\hline
\end{tabular}

Table 5 Landscape metric values based on threshold continuum approach for both dates.

\begin{tabular}{cccccccccc}
\hline Landscape metrics/ Percent ISA & \multicolumn{2}{c}{$>10 \%$} & \multicolumn{2}{c}{$>30 \%$} & \multicolumn{3}{c}{$>50 \%$} & \multicolumn{2}{c}{$>70 \%$} \\
\hline & 1989 & 2001 & 1989 & 2001 & 1989 & 2001 & 1989 & 2001 \\
\cline { 2 - 9 } PD & 6.01 & 8.15 & 6.08 & 8.23 & 5.51 & 6.53 & 5.9 & 8.24 \\
AI & 84.28 & 83.39 & 84.25 & 83.39 & 80.89 & 91.924 & 74.35 & 71.68 \\
COHESION & 99.57 & 99.7 & 99.56 & 99.69 & 98.89 & 99.65 & 98.03 & 99.12 \\
LSI & 83.73 & 94.91 & 84.54 & 95.63 & 76.28 & 97.48 & 66.37 & 101.81 \\
PAFRAC & 1.44 & 1.49 & 1.43 & 1.49 & 1.49 & 1.48 & 1.50 & 1.50 \\
\hline
\end{tabular}

